\title{
Prospects for the application of film-forming amines in power engineering
}

\author{
A. V. Ryzhenkov, S. I. Pogorelov, A. V. Kurshakov, \\ M. A. Morozov \& N. V. Ryzhenkova \\ Moscow Power Engineering Institute, National Research University, \\ Russia
}

\begin{abstract}
The current state of the power engineering industry of the Russian Federation is characterized by high wear, low energy efficiency and the necessity for the reconstruction and modernization of a considerable amount of its energy facilities. Due to the impossibility of the construction and commissioning of a large number of facilities, the development and implementation of technologies, as well as and extending the lifespan of existing equipment in order to improve energy efficiency of power plants, remain urgent tasks. Film-forming amines are well known (Moscow Power Engineering Institute, National Research University (MPEI NRU) has been using them for over 40 years now) and are widely used in power engineering. On the basis of numerous experimental studies and industrial approbations, MPEI NRU have designed a group of technologies to address some of the problems encountered in the operation of power equipment.

A wider implementation of the developed technologies will significantly improve the efficiency, reliability and service life of power units and NPP second circuits.

Keywords: heat and power engineering, heat supply systems, energy efficiency, film-forming amines, surfactants, octadecylamine, hydrophobicity, corrosion, energy loss, hydraulic resistance, turbine.
\end{abstract}

\section{Introduction}

In modern times, the power engineering industry of Russia is in dire need of technology that could prolong the resources of newly commissioned and already- 
in-use equipment. Also, such technology could increase the efficiency of thermal and nuclear power plants' power units.

Several problems arising from the operation of energy and thermal power equipment can be solved by technologies that have been developed at Moscow Power Engineering Institute National Research University (MPEI NRU) in recent years. These technologies are based on the properties of the surfactants - in particular, the film-forming amines, including:

1) block corrosion processes for the period of repairs and long periods of inactivity (preservation);

2) increasing operating efficiency of heating systems based on the recovery of the design characteristics and life extension;

3) reducing the intensity of droplet erosion destruction of the last stages blades of steam turbines by significantly reducing the size of the droplet phase;

4) improving energy efficiency of the boiler and turbine equipment by removing the accumulated deposits and ensuring a sharp decline in the formation rate of new deposits of various natures of origin;

5) reducing energy consumption to the actuator of pumping equipment by reducing the flow resistance during the aqueous media and hydrocarbon transportation phase;

6) improving energy efficiency of power units of thermal and nuclear power plants by transferring the filmwise condensation to the dropwise condensation in capacitors' steam-turbine plant.

Surfactants such as film-forming amines possess a number of unique properties, the combination of which determines the possibility of their successful application in the energy sector.

Under certain conditions, some film-forming amines (FFA) are formed on the metal surfaces of closely packed molecular layers due to the processes of physical or chemical sorption.

One of the most distributed FFAs is octadecylamine, which is a white waxy solid with the chemical formula $\mathrm{C}_{18} \mathrm{H}_{37} \mathrm{NH}_{2}$.

Numerous studies conducted over the last 50 years at MPEI NRU, the AllRussian Thermal Engineering Institute (JSC VTI), the All-Russia Research and Design Institute of Nuclear Machine Engineering (JSC VNIIAM) and other institutions [1-12] allowed for the determination of most of the FFA properties and molecular layers formed by them, including:

- The temperature limits of applicability;

- Sorption values for various metals and alloys;

- Sorption dependence on velocity, concentration, reaction time and other parameters.

\section{Block corrosion processes for the period of repairs and long downtimes (preservation)}

The formation of FFA molecular layers on metal surfaces can significantly improve their corrosion resistance. Close-packed layers create a "physical" barrier to the entry of corrosive compounds to the metal surface (figures 1 and 2). 


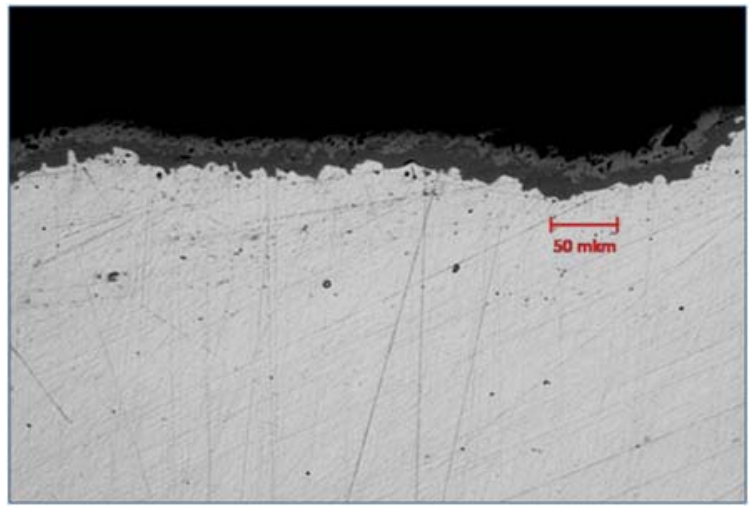

Figure 1: Fractograph of the thin section of pipe surfaces, with adsorbed FFA molecular layers. A high adhesion of layers to the metal surface (gray area) is clearly visible.

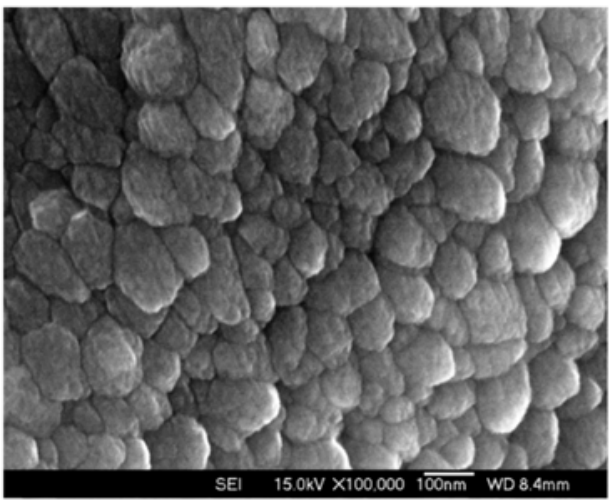

Figure 2: Close-packed structure on the metal surface after the formation of FFA molecular layers. Photograph taken using an electron microscope.

The formation of molecular layers occurs due to the action of electric and molecular interaction forces. One feature of the FFA molecules is the polarity that causes interaction with the negative potential of the metal surfaces. Figure 3 shows the arrangement of atoms in a molecule of octadecylamine, the distinguishing feature of which is a linear structure.

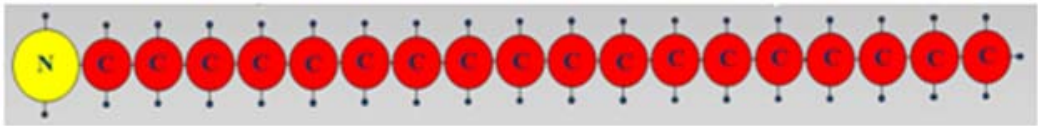

Figure 3: Scale arrangement of atoms in a FFA molecule (hydrogen atoms are marked by the smallest shaded circles). 
The conservation of energy equipment using FFA has been proven effective for more than 300 objects and it is more cost-effective than common methods applied today $[1-4]$.

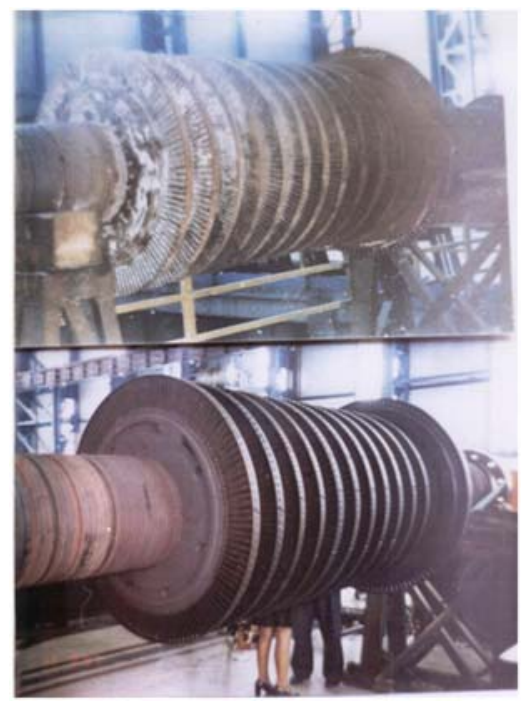

Figure 4: Turbine rotor of $200 \mathrm{MW}$ before and after preservation using FFA.

In the process of preserving energy equipment, another form of FFA property displacement, for pores and cracks on the functional surfaces of equipment corrosive compounds such as chlorides, which allows carrying out highly efficient cleaning of the surface, is used (fig. 5).

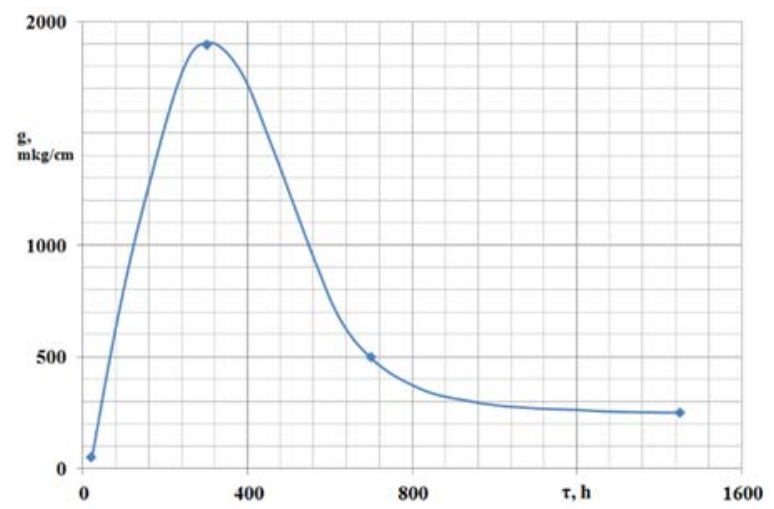

Figure 5: Dependence of the chloride concentration in the feed water on the formation of FFA molecular layers. Concentration leap is clearly visible due to chlorides displacement from the surface of the pores and cracks. 


\section{Improving the efficiency of heat supply systems}

The conditioning of a heat carrier by FFA molecules and, consequently, the formation of molecular layers, can significantly improve the energy efficiency of heat supply systems, restore piping and equipment sections, locking the corrosion processes and dramatically slowing down the processes of formation deposits of different natures [5-9].

Figure 6 shows the effect of FFA molecular layers on the kinetics formation layers of carbonate deposits; from the presented dependences it is obvious that the rate of accumulation of deposits has decreased by 8-12 times.

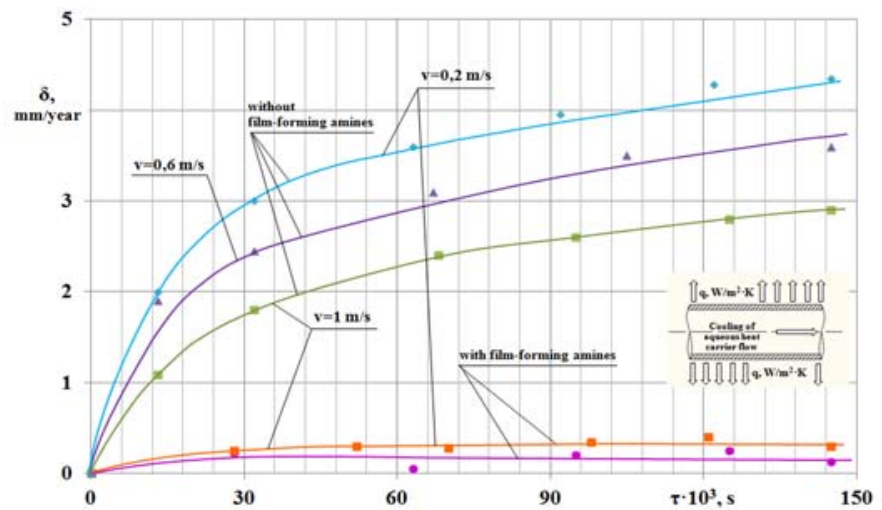

Figure 6: Kinetics formation deposits on the surface of steel pipe samples in a hydrocarbonate water flow at $50^{\circ} \mathrm{C}$.

The high efficiency of the technology and a significant reduction in gas consumption in the operation of boiler plants from $2 \%$ to $9 \%$ (based on analysis of more than 20 objects) have been demonstrated by the Open joint-stock company Moscow United Electric Grid Companies (MOESK).

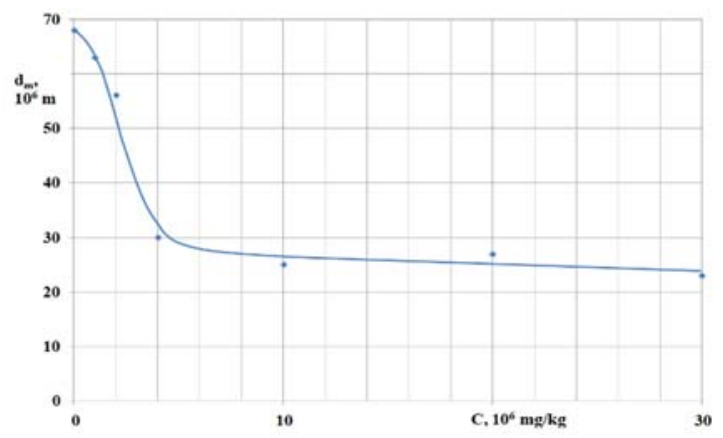

Figure 7: Dependence of the modal droplet size at the last stage turbine of Dimitrov's heat station in Leipzig on the concentration of FFA molecules. 


\section{Reduction of the droplet erosion destruction intensity of the last stages of steam turbines blades}

By using another FFA feature - reducing the surface tension of water - the lifespan of last stages turbine blades can be improved. FFA micro-dosage in the flow part of the steam-turbine plant allows a significant reduction (3-4 times) in the modal size of the droplet phase in the steam flow which, as a result, reduces the impact on the blades surface, which is especially important for high-power turbine units with long blades at the last stages.

\section{Improving energy efficiency of the boiler and turbine equipment}

FFA molecules can loosen and reject deposits from the functional surfaces of power equipment. Figure 8 shows the fragments of a hot water piping system before and after the formation of FFA molecular layers. By lowering the FFAmolecules' surface tension of water, molecules, along with water, penetrate the pores of iron-oxides, carbonaceous composites and other deposits, tending to metal the surface due to the electric forces action (figure 9). Cleaning the functional surfaces can significantly improve the efficiency and lifespan of the boiler and turbine equipment [5,9].

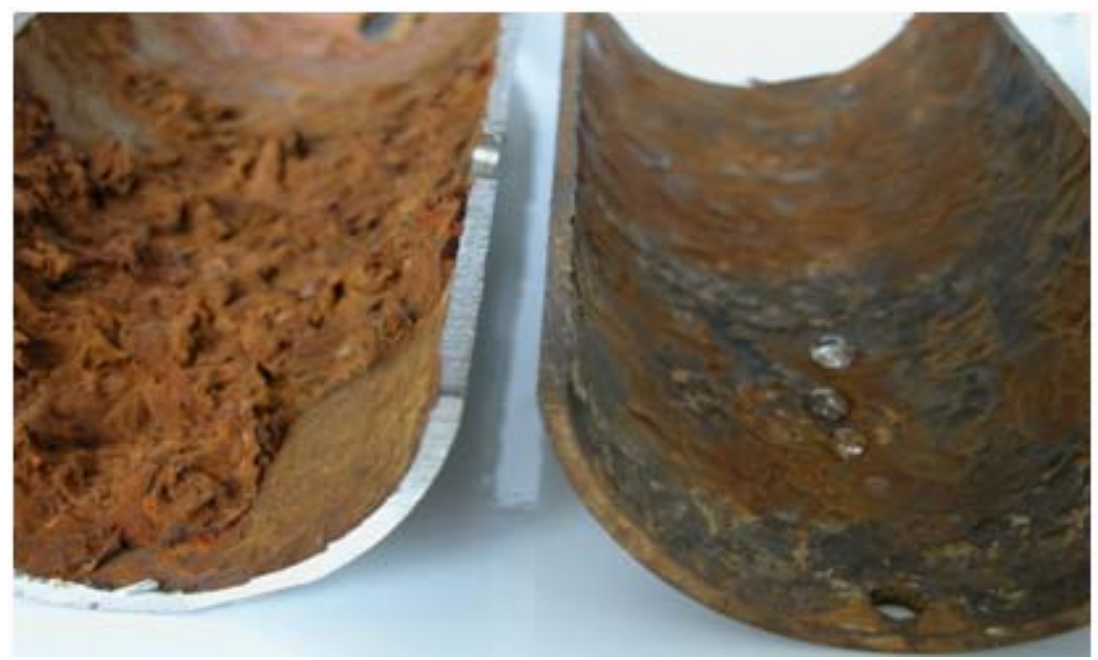

(a)

(b)

Figure 8: The surface condition of hot water distribution networks piping before (a) and after (b) formation of FFA molecular layers. 

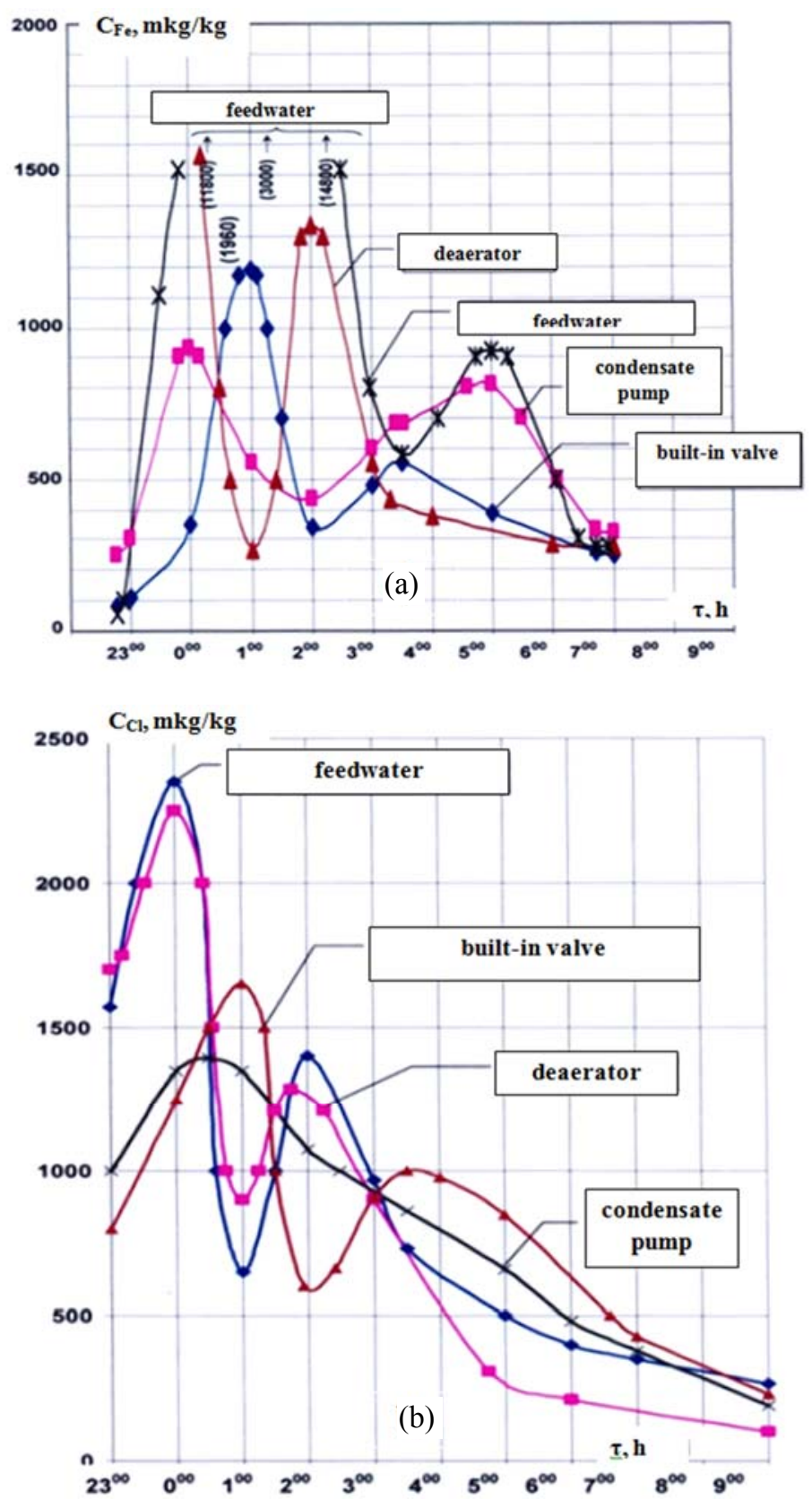

Figure 9: Change in the concentration of iron (a) and chlorides (b) in tracts of equipment $300 \mathrm{MW}$ power unit during formation of FFA molecular layers. 


\section{Reducing energy consumption to the actuator of pumping equipment}

FFA molecular layers significantly change the surface properties of conventional constructional materials, which leads to significant improvements in terms of hydrodynamic characteristics, reduction of the hydraulic resistance of pipelines and equipment up to $20-38.5 \%$ in the range of $0.5-2.5 \mathrm{~m} / \mathrm{s}$ heat carrier flow velocity (figure 10).

Such a significant effect of reducing flow resistance is caused by a reduction of the surfaces' relative roughness, in other words - "smoothing" of the relief surfaces. According to modern ideas about the nature of turbulence, the main resistance to fluid flow in a turbulent flow in pipes is exerted by turbulent eddies which are characterized by intensity and length. Conditions of flow around the surface are changing by a transported working body when FFA molecular layers are formed on the surface, whereas a portion of turbulent eddies are "damping" and the rest are weakening [5, 6, 8-10].

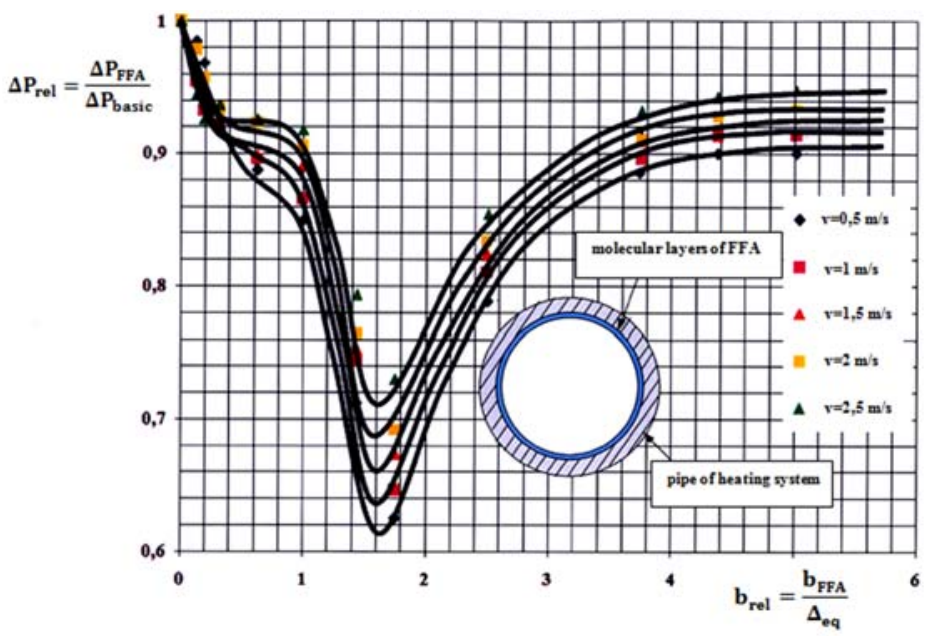

Figure 10: Influence of the thickness of FFA molecular layers formed on the intratubal surface on the magnitude of the hydraulic resistance of the pipeline.

\section{Improving energy efficiency of power units of thermal and nuclear power plants}

One of the most effective ways of intensification of heat exchange for the steam side of the capacitor in steam-turbine plants is for transfer film condensation to dropwise condensation by hydrophobisation the outer surface of the tubes (figure 11). 

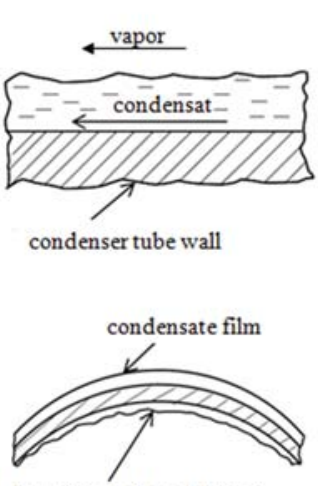

deposits on the condenser
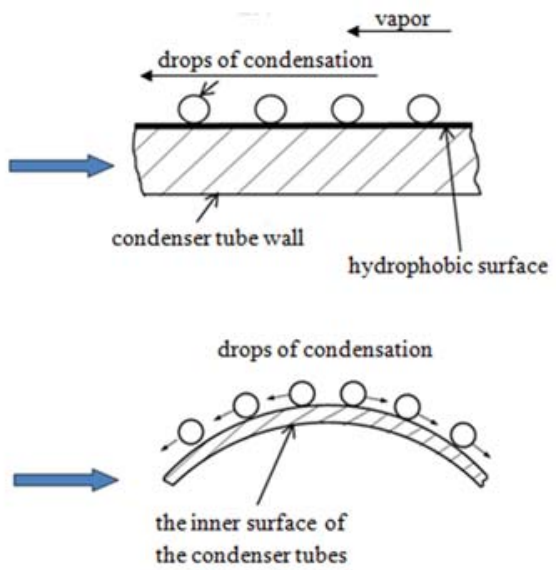

Figure 11: Explanation of the method to modify functional surfaces of condenser tubes in turbo-installations power units' heat and power plants.

When there is film condensation, heat is transferred from vapor to wall through the film of the condensate and this film represents the main thermal resistance. When there is dropwise condensation, thermal resistance is absent or greatly reduced. Steam is in direct contact with the wall on the section of the surface in between the drops. If there is film condensation of $\alpha \approx 4660-17,440\left[\mathrm{~W} / \mathrm{m}^{2}{ }^{\circ} \mathrm{K}\right]$, then there is dropwise condensation of $\alpha \approx 4660-139,660\left[\mathrm{~W} / \mathrm{m}^{2}{ }^{\circ} \mathrm{K}\right]$.

Detailed analysis, laboratory and industrial tests allowed for the consideration of the FFA condenser tubes' surface, where molecules can be sorbed during an equipment shutdown period or in the period of operation by the injection of steam, as a promising hydrophobizator (figure 12).

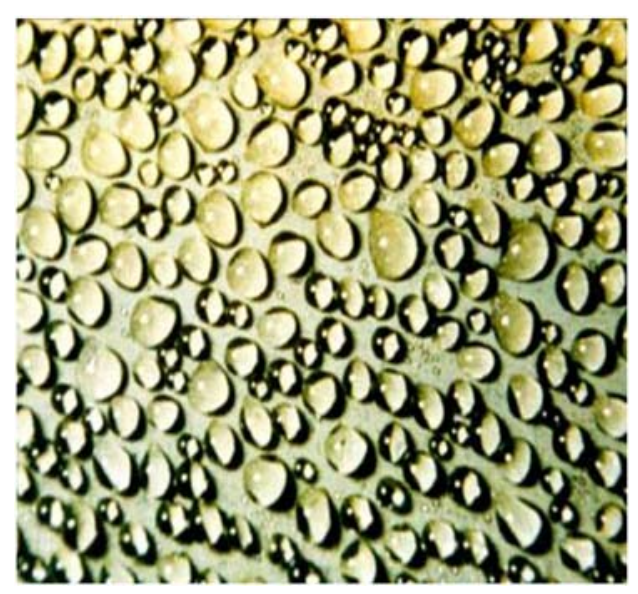

Figure 12: Hydrophobicity of brass condenser tubes (steam side) after adsorption of FFA molecules on the surface. 
Analysis of the data has demonstrated that the intensity of heat transfer during dropwise condensation was significantly higher than in the film condensation in all operating modes of the condensate. The heat transfer coefficient of the steam condenser in the transition from the film condensation to dropwise condensation increases according to the heat-and-hydraulic operation mode by $1.75-3$ times. At the same time, the reduced heat transfer coefficient on the steam side increases by $8-11$ times $[11,12]$.

The modification of outer surfaces of the condenser tubes using FFA also promotes intensification of heat and mass transfer in the intertube space due to additional dispersion of condensate, which ultimately leads to lower condensate supercooling.

\section{Conclusion}

Thus, the use of film-forming amines can significantly improve the energy efficiency of power equipment, block corrosion processes, and dramatically reduce the rate of deposition of layers of different natures.

\section{Acknowledgement}

The reported study was partially supported by RFBR, research project No. 13-0801346 a.

\section{References}

[1] Kurshakov, A. V., Filippov, G. A., Kukushkin, A. N., Saltanov, G. A., Velichko, E. V., Mihajlov, V. A., Petrova, T. I., Chempik, J., Voronina, M. P., Ryzhenkov, V. A., Balajan, R. S, Conservation of energy-using equipment based on film-forming amines, Thermal Engineering, 9, 1999.

[2] Kurshakov, A. V., Ryzhenkov, V. A., Kulov, V. E., Experience of conservation 200MW units on power plant in Shatura, Russia, Theses of reports Jubilee STC MPEI, 2000.

[3] Kurshakov, A. V., Dubrovskij, I. Ja., Polevoj, E. N., Ryzhenkov, V. A., Samarenko, V. N., Tazhiev, Je. N., Shanko, V. N., Conservation turbines by aqueous emulsion of octadecylamine, Energy saving and water treatment, 3, 2001.

[4] Ryzhenkov, V. A., Kurshakova, A. V., Anahov, I. P., Zagretdinov, I. Sh., Gorohova, O. V., About the effectiveness thermal power equipment protection against atmospheric corrosion during repairs and long periods of inactivity, Reliability and security of energy, 1(8), pp. 43-46, 2010.

[5] Ryzhenkov, V. A., About increase of operating efficiency of domestic heating systems in modern conditions, News of heat supply, 9(73), pp. 3642, 2006.

[6] Ryzhenkov, V. A., Kurshakov, A. V., Ryzhenkov, A. V., Pulner, I. P., Shherbakov, S. N., About increase of operational efficiency of urban 
heating systems based on SAW technology, News of heat supply, 12, pp. 45-50, 2007.

[7] Kurshakov A. V., Nefedkin S.I., Ryzhenkov V. A., Kukushkin A. N., Determination of efficacy parameters of film-forming corrosion inhibitors, New in Russian power, 7, pp. 38-43, 2008.

[8] Volkov, A. V., Davydov, A. I., Hovanov, G. P., On the issue of energy efficiency superhydrophobicity centrifugal pumps, Pumps and equipment, 6(59), pp. 48-51, 2009.

[9] Ryzhenkov, V. A., Kurshakov, A. V., Anahov, I. P., About increase of operating efficiency of heat supply systems and heating systems based on thermal barrier to prevent the accumulation of deposits on the functional surfaces of equipment, Power and Water Treatment, 3, pp. 31-33, 2010.

[10] Ryzhenkov, A. V., Morozov, M. A., Jurenko, O. V., Current state of pipeline systems for transporting fluids and hydrocarbons, Natural and engineering sciences, 4(60), pp. 334-338, 2012.

[11] Ryzhenkov, V. A., Kurshakov, A. V., Anahov, I. P., Sviridova, E. V., On improving the efficiency and reliability of operation of steam turbines condensers, Power and Water Treatment, 2(52), pp. 29-34, 2008.

[12] Ryzhenkov, V. A., Kurshakov, A. V., Anahov, I. P., Improving operational efficiency of steam turbines condensers based on modifying the pipe surfaces using surfactants, New in the Russian power, 5, pp. 27-33, 2008. 